\title{
Porcas lactantes alimentadas com dietas contendo silagem de grãos úmidos de milho e ácidos orgânicos
}

\author{
Lactating sows fed with high moisture corn diets and organic acids
}

\author{
Paulo Alberto LovattoI Volnei Antônio Weschenfelder ${ }^{\text {II }}$ Carlos Augusto Rigon Rossi ${ }^{I I}$ \\ Cheila Roberta Lehnen ${ }^{\text {II }}$ Ines Andretta ${ }^{\text {II }}$
}

\begin{abstract}
Um experimento foi realizado para avaliar o RESUMO desempenho de porcas lactantes e suas leitegadas alimentadas com dietas contendo silagem de grãos úmidos de milho com ou sem ácidos orgânicos. Foram utilizadas 15 porcas híbridas em um delineamento de blocos ao acaso com três tratamentos (dieta controle, dieta com adição de 0,5\% de ácido benzóico e dieta com adição de 0,5\% de ácido fumárico) com cinco repetições cada. As dietas elaboradas com silagem de grãos úmidos de milho com ácido benzóico ou ácido fumárico não alteraram $(P>0,05)$ a espessura de toucinho e o consumo médio diário de ração. O ganho médio diário $(0,22 \mathrm{~kg})$ e o peso vivo médio ao desmame $(6,2 \mathrm{~kg})$ dos leitões não diferiram $(P>0,05)$ entre os tratamentos. A adição dos ácidos fumárico e benzóico nas dietas elaboradas com silagem de grãos úmidos de milho não altera os desempenhos de porcas lactantes e de suas leitegadas.
\end{abstract}

Palavras-chave: ácido benzóico, ácido fumárico, escore corporal, leitegadas, suínos.

\section{ABSTRACT}

An experiment was carried out to evaluate the performance of lactating sows and their piglets fed with high moisture corn diets with or without organic acids. Fifteen sows were used in a randomized complete block with three treatments (control diet; control diet with $0.5 \%$ of benzoic acid; control diet with $0.5 \%$ of fumaric acid) with five replications each. The diets were elaborated within a $24 \mathrm{~h}$ period. Diets elaborated with high moisture corn with benzoic or fumaric acids did not modify $(P>0.05)$ the backfat thickness and the average daily feed intake. The average daily weight gain $(0.22 \mathrm{~kg})$ and average weaning live weight $(6.2 \mathrm{~kg})$ of piglets were not influenced $(P>0.05)$ between treatments. The addition of organic acids in diets containing high moisture corn does not alter the performance of lactating sows and piglets.

Key words: benzoic acid, body score, fumaric acid, performance, piglets.

A nutrição representa cerca de $75 \%$ do custo da produção suína. Em vista da disponibilidade e de suas qualidades nutricionais, o milho e o farelo de soja são os principais ingredientes de rações para suínos no Brasil. Porém, o uso do milho na forma de silagem permite antecipar o período de colheita em até 30 dias, reduzindo perdas pós-colheita e custos com secagem de armazenamento (OLIVEIRA et al., 2004).

A ensilagem garante a qualidade sanitária dos grãos e melhora a disponibilidade de seus nutrientes. As vantagens técnicas e econômicas da silagem de grãos úmidos de milho têm favorecido sua utilização nas dietas de suínos. A retirada de silagem diariamente, no entanto, expõe a massa ensilada ao desenvolvimento de microorganismos (WARDYNSKY et al., 1993).

A exposição ao ar torna metabolicamente ativos alguns microorganismos oportunistas que

IDepartamento de Zootecnia (DZ), Universidade Federal de Santa Maria (UFSM), 97105-900, Santa Maria, RS, Brasil. E-mail: lovatto@smail.ufsm.br. Autor para correspondência.

IIPrograma de Pós-graduação em Zootecnia (PPGZ), DZ, UFSM, Santa Maria, RS, Brasil.

IIICurso de Zootecnia, UFSM, Santa Maria, RS, Brasil. 
produzem calor e consomem nutrientes da silagem. Além disso, a proliferação de bactérias do gênero Clostridium, de enterobactérias, fungos e leveduras, pode prejudicar a qualidade da silagem e provocar transtornos sanitários aos animais (RANJIT \& KUNG JR, 2000).

Nesse contexto, a alteração química, sobretudo de $\mathrm{pH}$ da dieta, pode ser uma alternativa viável para o controle desses microorganismos. Adicionalmente, respostas positivas da utilização de ácidos orgânicos foram verificadas em leitões em creche e suínos em crescimento (MROZ, 2005). No entanto, há poucas informações no Brasil sobre a utilização de aditivos ácidos em dietas elaboradas com silagem de grãos úmidos de milho. Assim, este trabalho teve como objetivo avaliar o desempenho de porcas lactantes com dietas contendo silagem de grãos úmidos de milho e ácidos orgânicos.

O trabalho foi realizado de abril a maio de 2007, em uma granja comercial situada na região central do Rio Grande do Sul. Foi utilizado um rebanho de 15 porcas híbridas Large White x Landrace inseminadas artificialmente, de ordens de parto de um a oito, com 11 leitões lactentes em média. O período experimental foi de 23 dias (dois dias pré-parto e 21 dias de lactação). Os grãos úmidos de milho foram armazenados com $28 \%$ de umidade sem a adição de inoculantes, ensilados por 120 dias, até a abertura para utilização na fabricação de rações pela granja. Foram utilizados os ácidos benzóico e fumárico feed grade, com apresentação sólida cristalina e grau de pureza de $99,9 \%$. O delineamento experimental foi o de blocos ao acaso, com três tratamentos (dieta controle - DC, DC + 0,5\% de ácido benzóico e DC + 0,5\% de ácido fumárico) e cinco repetições cada, sendo a porca e a leitegada utilizadas como unidade experimental. $\mathrm{O}$ fator de bloqueamento consistiu nas ordens de parto (OP) distribuídas em bloco 1 (OP 1 a 3), bloco 2 (OP 4 a 6) e bloco 3 (OP =7 partos). As leitegadas foram homogeneizadas em número de 11 leitões nos diferentes grupos de ordem de parto. As porcas lactantes receberam dietas isonutritivas e formuladas segundo as exigências nutricionais do NRC (1998), ajustadas com base na matéria seca do milho em $12 \%$ de umidade.

As dietas foram elaboradas de acordo com as condições de fabricação e manejo de rotina da granja comercial. A silagem foi retirada do silo pela manhã e armazenada em sacos de polipropileno. Foram elaboradas, previamente, pré-misturas da silagem, ácidos orgânicos e suplemento vitamínico e mineral em $10 \%$ das misturas totais. As dietas foram misturadas por $4 \mathrm{~min}$ em misturador vertical com capacidade de 500 quilogramas. As dietas foram fornecidas na primeira semana às 7,13 e $18 \mathrm{~h}$ e na segunda e na terceira semanas às 7, 13, 18 e 24h. As sobras de ração foram coletadas e pesadas para estimar o consumo real de alimento. As porcas receberam alimentação e água à vontade. Os leitões receberam ração comercial micropeletizada fornecida à vontade a partir dos sete dias de idade. A ventilação das salas foi controlada com abertura e fechamento de cortinas.

As variáveis medidas e estimadas nas porcas foram (a) peso, estimado a partir de medidas de flanco a flanco nas inserções das pregas cutâneas abdominais com os membros posteriores, passando pela região das últimas vértebras lombares (YOUNG \& AHERNE, 2005); (b) espessura de toucinho, medida com aparelho de ultra-som Renco Lean Meater a 5,5cm da linha média lombar na região da última costela, em ambos os lados (YOUNG \& AHERNE, 2005); (c) consumo de ração, com pesagem das sobras após cada arraçoamento e ao final de cada dia experimental, às 14h; e (d) conversão alimentar das porcas, determinada por meio do consumo diário de ração das porcas dividido pelo ganho de peso diário da leitegada. As variáveis medidas e estimadas nos leitões foram pesos no nascimento, a cada semana e na saída da maternidade (das leitegadas e ganho diário). Os fatores de ordem de parto foram analisados preliminarmente, porém os seus efeitos não foram significativos, sendo retirados do modelo analítico. Os dados obtidos foram submetidos à análise de variância pelo procedimento GLM. As eventuais diferenças entre as médias foram comparadas pelo Teste de Tukey com 5\% de significância. As análises estatísticas foram realizadas com o programa estatístico Minitab (MCKENZIE \& GOLDMAN, 1999).

Os resultados das porcas alimentadas com dietas SGUM contendo ácidos orgânicos são apresentados na tabela 1 . Não houve efeito $(P>0,05)$ dos ácidos orgânicos sobre o peso estimado e a espessura de toucinho das porcas. A redução da espessura de toucinho ao final da lactação $(P>0,05)$ foi de $1,4 \mathrm{~mm}$ para o controle, $1,0 \mathrm{~mm}$ para o ácido benzóico e 2,8mm para ácido fumárico. De maneira geral, quando comparadas aos estudos de YOUNG \& AHERNE (2005) e YOUNG et al. (2005), as variações de espessura de toicinho durante a lactação foram menores. Neste estudo, no entanto, as variações não foram suficientes para alcançar o limite de $14,0 \mathrm{~mm}$ de espessura que poderia comprometer a eficiência reprodutiva das porcas nos ciclos subseqüentes.

Não houve influência $(\mathrm{P}>0,05)$ dos ácidos orgânicos sobre o consumo diário de ração e a conversão alimentar. É provável que a adição dos ácidos 
Tabela 1 - Desempenho de porcas lactantes alimentadas com dietas contendo silagem de grãos úmidos de milho com ou sem ácidos orgânicos.

\begin{tabular}{|c|c|c|c|c|c|}
\hline Período, d & Controle & Tratamento Benzóico & Fumárico & epr $^{1}$ & $\mathrm{P}^{2}$ \\
\hline 0 & 207 & 218 & 224 & 259 & 0.70 \\
\hline 7 & 212 & 224 & 233 & 24,9 & 0,55 \\
\hline 14 & 217 & 231 & 217 & 26,3 & 0,70 \\
\hline 21 & 219 & 230 & 210 & 24,6 & 0,50 \\
\hline 0 & 16,0 & 15,8 & 17,8 & 7,3 & 0,88 \\
\hline 7 & 16,0 & 16,0 & 17,8 & 6,7 & 0,86 \\
\hline 14 & 15,8 & 16,0 & 16,4 & 6,0 & 0,99 \\
\hline 21 & 14,6 & 14,8 & 15,0 & 5,6 & 0,99 \\
\hline 7 & 6,06 & $\begin{array}{l}\text { isumo médio } \\
6,83\end{array}$ & 6,19 & 0,5 & 0,20 \\
\hline 14 & 8,24 & 9,20 & 8,56 & 0,8 & 0,16 \\
\hline 21 & 8,55 & 9,02 & 8,45 & 0,5 & 0,26 \\
\hline Média & 7,62 & 8,35 & 7,81 & 0,5 & 0,14 \\
\hline Período total & 159,90 & 175,30 & 164,20 & 12,1 & 0,14 \\
\hline & & -----Conversão alim & & & \\
\hline 7 & 6,40 & 5,09 & 4,29 & 2,20 & 0,34 \\
\hline 14 & 6,19 & 6,52 & 4,15 & 3,57 & 0,51 \\
\hline 21 & 6,00 & 5,81 & 4,83 & 1,56 & 0,47 \\
\hline
\end{tabular}

${ }^{1}$ erro-padrão residual; ${ }^{2}$ probabilidade $(\mathrm{P}<0,05) ;{ }^{3} \mathrm{~kg}$ alimento consumido porca $\mathrm{kg}^{-1}$ ganho leitegada.

fumárico e benzóico não interfira na palatabilidade das dietas. Alguns ácidos podem interferir no consumo de ração devido à liberação de fortes odores e ao sabor pungente, observados também nos ácidos benzóico e fumárico (PARTANEN \& MROZ, 1999). A manipulação química realizada por meio de encapsulamento ou formação com sais de Ca e K (feed grade) limitam a volatilização de odores. Dessa forma, essa apresentação física de ácidos não interfere na palatabilidade das dietas (MROZ, 2005).

Os resultados de desempenho das leitegadas são apresentados na tabela 2. Não houve efeito $(\mathrm{P}>0,05)$ dos ácidos orgânicos sobre o peso vivo e o ganho de peso das leitegadas. De maneira geral, houve uma variação positiva de peso aos 21 dias em relação ao controle de $9 \%$ e $16 \%$ (P>0,05) para as dietas com ácidos benzóico e fumárico, respectivamente. Porcas alimentadas com dietas acidificadas apresentam respostas positivas sobre a digestão de energia, proteína e balanço de nitrogênio (PARTANEN \& MROZ, 1999). Por meio do metabolismo intermediário, os ácidos orgânicos podem influenciar na quantidade de leite produzido (JONGBLOED et al., 2000). É provável que a ingestão de ácidos orgânicos pelas porcas interferiu na eficiência digestiva e metabólica dos nutrientes, correspondendo a um efeito adicional na produção de leite. Assim, ela pode ser responsável pela melhora no fornecimento dos nutrientes essenciais aos leitões e pela síntese protéica, aumentando a digestibilidade ileal de aminoácidos e o ganho de peso dos leitões (BLANK et al., 1999).

A utilização de ácidos orgânicos na alimentação de suínos apresenta respostas variáveis (PARTANEN \& MROZ, 1999). Contudo, a utilização desses aditivos apresenta efeitos positivos na digestão e no metabolismo de nutrientes e no controle de microorganismos patogênicos (BLANK et al., 1999). Os efeitos positivos do ácido fumárico verificados neste estudo nas variáveis ganho de peso e peso vivo ao desmame corroboram os resultados obtidos em leitões em creche (PARTANEN \& MROZ, 1999). Diante disso, as respostas obtidas permitem propor novos estudos de desempenho em porcas lactantes, com ajuste de dose e possível uso como conservantes de dietas.

A adição dos ácidos fumárico e benzóico em dietas elaboradas com silagem de grãos úmidos de milho não altera o desempenho de porcas lactantes e de suas leitegadas.

Ciência Rural, v.39, n.4, jul, 2009. 
Tabela 2 - Peso vivo médio e ganho médio diário de leitegadas de porcas lactantes alimentadas com dietas contendo silagem de grãos úmidos de milho com ou sem ácidos orgânicos.

\begin{tabular}{|c|c|c|c|c|c|}
\hline Período, d & Controle & Tratamento Benzóico & Fumárico & epr $^{1}$ & $\mathrm{P}^{2}$ \\
\hline \multicolumn{6}{|c|}{ 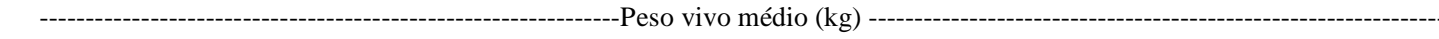 } \\
\hline 0 & 1,36 & 1,39 & 1,32 & 0,15 & 0,84 \\
\hline 7 & 2,45 & 2,82 & 2,79 & 0,39 & 0,44 \\
\hline 14 & 4,18 & 4,57 & 4,86 & 0,95 & 0,60 \\
\hline 21 & 5,71 & 6,25 & 6,63 & 1,36 & 0,59 \\
\hline & & Ganho médi & ') & & ------ \\
\hline 7 & 0,14 & 0,18 & 0,19 & 0,05 & 0,19 \\
\hline 14 & 0,25 & 0,25 & 0,30 & 0,08 & 0,58 \\
\hline 21 & 0,22 & 0,23 & 0,25 & 0,08 & 0,75 \\
\hline Média & 0,20 & 0,22 & 0,25 & 0,06 & 0,48 \\
\hline
\end{tabular}

${ }^{1}$ erro-padrão residual; ${ }^{2}$ probabilidade $(\mathrm{P}<0,05)$.

\section{REFERÊNCIAS}

BLANK, R. et al. Effect of fumaric acid and dietary buffering capacity on ileal and fecal amino acid digestibilities in earlyweaned pigs. Journal of Animal Science, v.77, p.29742984, 1999.

JONGBLOED, A.W. et al. The effects of microbial phytase, organic acids and their interaction in diets for growing pigs. Livestock Production Science, v.67, p.113-122, 2000. Disponível em :http:// w w w. S c i e n c e d i r e c t. c o m / science?_ob=ArticleURL\&_udi=B6T9B-41SKB1KC\&_user $=687358 \& \_r d o c=1 \&$ fmt $=$ \&_orig=search\&_sort $=$ d\&view $=$ c \&_acct $=$ C000037899\&_version $=1 \&$ \&_urlVersion $=$ $0 \&$ \& u e r i d $=687358 \& \mathrm{~m} \mathrm{~d} 5=163$ c3b20ad476b6945797ee0939313cf. Doi: 10.1016/S03016226(00)00179-2.

MCKENZIE, J.; GOLDMAN, R.N. The student edition of Minitab for Windows manual. Belmont: Softcover ed. Addison-Wesley Longman, 1999. V.12, 592p.

MROZ, Z. Organic acids as potential alternatives to antibiotic growth promoters for pigs. Advances in Pork Production, v.16, p.169-182, 2005.

NRC National Research Council. Nutrient requirements of swine. Washington: National Academy of Science, 1998. V.10, 189p.
OLIVEIRA, R.P. et al. Valor nutritivo e desempenho de leitões alimentados com rações contendo silagem de grãos úmidos de milho. Revista Brasileira de Zootecnia, v.33, p.146-156, 2004. Disponível em: http://www.scielo.br/scielo.php?script=sci_arttext\&pid=S151635982004000100019\&lng=en\&nrm=iso\&tlng=pt. Doi: 10.1590/ S1516-35982004000100019.

PARTANEN, K.H.; MROZ, Z. Organic acids for performance enhancement in pig diets. Nutrition Research Reviews, v.12, p.117-145, 1999. Disponível em: http://journals.cambridge.org/ action/displayAbstract? fromPage $=$ online \&aid=547616. Doi: 10.1079/095442299108728884

RANJIT, N.K.; KUNG JR, L. The effect of Lactobacillus buchneri, Lactobacillus plantarun, or a chemical preservative on the fermentation and aerobic stability of corn silage. Journal of Dairy Science, v.83, n.3, p.526-535, 2000.

WARDYNSKY, F.A. et al. Effect of microbial inoculation of high-moisture corn on fermentation characteristics, aerobic stability and cattle performance. Journal Animal Science, v.71, p.2246-2252, 1993.

YOUNG, M.; AHERNE, F. Monitoring and maintaining sow condition. Advances in Pork Production, v.16, p.299, 2005.

YOUNG, M.G. et al. Effect of sow parity and weight at service on target maternal weight and energy for gain in gestation. Journal of Animal Science, v.83, p.255-261, 2005. 